\title{
INTERAKSI GURU DENGAN KANAK-KANAK MENGGUNAKAN KEMAHIRAN BERFIKIR ARAS TINGGI
}

\section{TEACHER CHILD INTERACTION USING HIGH LEVEL THINKING SKILLS}

\author{
Zaharah Osman ${ }^{1}$ \\ Fakulti Pembangunan Manusia, Universiti Pendidikan Sultan Idris (UPSI), Malaysia. \\ (Email: zaharah@fpm.upsi.edu.my) \\ Azizah Zain ${ }^{2}$ \\ Fakulti Pembangunan Manusia, Universiti Pendidikan Sultan Idris (UPSI), Malaysia. \\ (Email: azizah.zain@fpm.upsi.edu.my) \\ Mazlina Che Mustafa ${ }^{3}$ \\ Fakulti Pembangunan Manusia, Universiti Pendidikan Sultan Idris (UPSI), Malaysia. \\ (Email: mazlina@fpm.upsi.edu.my)
}

Received date: 09-03-2019

Revised date: 02-04-2019

Accepted date: $19-08-2019$

Published date: 12-09-2019

To cite this document: Osman, Z., Zain, A., \& Che Mustafa, M. (2019). Interaksi Guru dengan Kanak-Kanak Menggunakan Kemahiran Berfikir Aras Tinggi. International Journal of Education, Psychology and Counseling, 4 (32), 20-28.

DOI: $10.35631 /$ IJEPC.432003

\begin{abstract}
Abstrak: Interaksi guru dengan kanak-kanak merupakan faktor penting dalam kejayaan proses pengajaran dan pembelajaran di prasekolah. Melalui interaksi semasa proses pengajaran dan pembelajaran di prasekolah, kanak-kanak boleh melibatkan diri dalam aktiviti yang dijalankan dan membantu kanak-kanak berfikir. Oleh itu, kajian ini bertujuan untuk mengkaji amalan interaksi guru dengan kanak-kanak yang berlaku semasa aktiviti bercerita menggunakan kemahiran berfikir aras tinggi. Kajian yang berbentuk kualitatif ini menggunakan instrumen pemerhatian, temu bual dan dokumen. Sesi rakaman video telah dijalankan sebanyak empat sesi yang berdurasi 30 minit setiap sesi di kelas prasekolah sewaktu aktiviti bercerita. Kemudian video tersebut dianalisis untuk mengenalpasti amalan interaksi antara guru dengan kanak-kanak menggunakan kemahiran berfikir aras tinggi. Sesi temu bual juga turut dijalankan bersama seorang guru sebagai sokongan kepada dapatan kajian. Hasil kajian menunjukkan bahawa guru menggunakan kemahiran berfikir aras rendah sahaja. Melalui hasil kajian yang dijalankan, para guru perlu mencari jalan untuk mengenalpasti penguasaan kemahiran berfikir aras tinggi dan dapat menjana daya pemikiran kanak-kanak dengan lebih baik.
\end{abstract}

Kata Kunci: Interaksi, Kemahiran Berfikir Aras Tinggi, Bercerita

Abstract: Teacher's interaction with children is an important factor in the success of the teaching and learning process in preschool. Through interactions during the teaching and learning process in preschools, children can engage in activities conducted and help children 
to think. Therefore, this study aims to examine the practice of teacher interaction with children during storytelling activities using high-level thinking skills. This qualitative study uses instruments of observation and interview. A video recording session was conducted for four sessions with a duration of 30 minutes per session in preschool classes during storytelling activities. Then the video was analysed to identify the interaction practices between teachers and children using high-level thinking skills. The interview session was also conducted with a teacher in supporting the findings. The results show that teachers use lowlevel thinking skills only. Through the results of the study, teachers need to find ways to identify the mastery of high-level thinking skills and to better empower children's thinking.

Keywords: Interaction, High Level Thinking Skills, Storytelling

\section{Pengenalan}

Interaksi yang baik antara guru dengan kanak-kanak boleh mewujudkan hubungan yang positif dalam kelas. Kepekaan guru terhadap suasana kelas akan memberi impak yang besar kepada guru dengan kanak-kanak itu sendiri. Persekitaran kelas yang kondusif terhasil apabila terdapat interaksi berkesan antara guru dengan kanak-kanak. Interaksi guru dengan kanak-kanak yang melibatkan kemahiran berfikir aras tinggi (KBAT), perlu dirancang dengan baik bagi menepati penggunaan aras soalan dalam proses pengajaran dan pembelajaran yang berkesan. Guru hendaklah bersedia dari segi pengetahuan KBAT dan menerapkan KBAT semasa berinteraksi dengan kanak-kanak.

\section{Pernyataan Masalah}

Sebahagian guru belum bersedia sepenuhnya atau masih kurang bersedia untuk melaksanakan KBAT dalam proses pengajaran dan pembelajaran (Norazilawati, Noraini, Mahizer \& Nik Azmah, 2014). KBAT ialah keupayaan untuk mengaplikasikan pengetahuan, kemahiran dan nilai dalam membuat penaakulan dan refleksi bagi menyelesaikan masalah, membuat keputusan, berinovasi dan berupaya mencipta sesuatu (KSPK, 2016). Guru perlu mempunyai kesediaan untuk melaksanakan KBAT dalam pengajaran mereka. Kesediaan dan keupayaan guru dalam menyampaikan KBAT masih rendah dan penggunaan kaedah konvensional dalam pengajaran masih meluas digunakan dalam kalangan guru (Mohamad Nurul Azmi et al. 2017). Keadaan ini boleh menyebabkan murid tidak menggunakan kemahiran berfikir secara optimum, tidak mendapat kemahiran mengemukakan soalan kepada guru atau rakan-rakan dan mengambil sikap berdiam diri kerana bimbang, tidak yakin diri dan malu.

Guru memainkan peranan penting dalam menyampaikan maklumat dan ilmu pengetahuan. Dalam proses pengajaran dan pembelajaran, tidak ada satu kaedah dan strategi yang khusus dan terbaik untuk diaplikasikan di dalam kelas yang mempunyai kepelbagaian murid (KSPK 2016). Walau bagaimanapun, guru yang menggunakan pendekatan pengajaran dan kaedah yang kurang berkesan akan menyebabkan pembangunan perlahan dalam proses kognisi dalam kalangan murid tadika (Suppiah, 2014). Guru perlu menguasai segala kemahiran yang diperlukan dalam pengajaran dan pembelajaran. Walau bagaimanapun, guru tidak menggunakan peluang sebaik-baiknya untuk mengajukan soalan beraras tinggi (Zamri 2011). Penggunaan penyoalan dalam proses pengajaran dan pembelajaran adalah proses mendapatkan jawapan yang betul, sekaligus membantu murid mendapatkan idea serta mengukuhkannya dalam bentuk pertuturan, tingkah laku dan penulisan.

Tindakan drastik Kementerian Pendidikan Malaysia untuk menerapkan KBAT dalam pengajaran dan pembelajaran betul-betul menguji guru agar bersedia. Pendedahan perlu 
diberikan kepada guru oleh pihak-pihak tertentu, agar pengetahuan guru berkaitan dengan KBAT dapat disampaikan kepada kanak-kanak. Kesediaan guru dari segi pengetahuan KBAT mampu memikirkan cara untuk meningkatkan KBAT pada diri kanak-kanak. Salah satu cara ialah menerapkan KBAT di dalam soalan-soalan semasa guru berinteraksi dengan murid sewaktu aktiviti bercerita. Ini kerana melalui penerapan KBAT dalam interaksi guru dengan murid sewaktu bercerita, murid akan terbiasa dan memudahkan mereka untuk menghadapi masalah harian.

Oleh itu, interaksi guru dengan kanak-kanak yang melibatkan KBAT, perlu dirancang dengan baik bagi menepati penggunaan aras soalan dalam proses pengajaran dan pembelajaran yang berkesan khasnya aktiviti bercerita. Kesediaan guru yang tinggi dari segi pengetahuan KBAT dan menerapkan KBAT semasa berinteraksi dalam aktiviti bercerita, boleh melahirkan kanak-kanak yang mampu menyelesaikan masalah secara rasional.

\section{Objektif kajian}

Tujuan kajian ialah untuk menyiasat interaksi guru dengan kanak-kanak menggunakan KBAT. Bagi memenuhi tujuan kajian, maka objektif kajian dibentuk supaya dapat melihat amalan penggunaan kemahiran berfikir aras tinggi dalam aktiviti bercerita melalui interkasi guru dengan kanak-kanak. Persoalan kajian yang digubal ialah apakah amalan penggunaan kemahiran berfikir aras tinggi dalam aktiviti bercerita melalui interaksi guru dengan kanakkanak?

\section{Skop kajian}

Kajian yang dijalankan ini berupa kajian kes dan menggunakan pemerhatian, temu bual dan dokumen. Sampel kajian terdiri daripada 4 orang guru yang mengajar di tadika. Beberapa batasan kajian dikenal pasti dalam kajian ini. Kajian ini hanya difokuskan kepada penggunaan KBAT dalam aktiviti bercerita melalui interaksi guru dengan kanak-kanak di daerah Muallim, Perak.

\section{Kajian Literatur}

Bahagian ini membincangkan tiga topik iaitu pengetahuan guru, elemen KBAT dalam pengajaran dan pembelajaran dan strategi pengajaran dan pembelajaran.

\section{Pengetahuan Guru}

Guru perlu mempunyai pengetahuan tentang KBAT yang disampaikan kepada kanak-kanak supaya kanak-kanak dapat menguasai kemahiran tersebut. Walau bagaimanapun, guru mempunyai pengetahuan yang kurang jelas tentang makna KBAT (Kassim \& Zakaria, 2015). Kajian Abdullah, Aris, Saud, Boon \& Awang Ali (2015) juga mendapati guru mengetahui aras kognitif Taksonomi Bloom secara asas namun mereka masih tidak memahami perbezaan dan fungsi bagi setiap aras dalam Kemahiran Berfikir Aras Rendah (KBAR) dan KBAT. Guru perlu menggunakan pengetahuan KBAT dan peluang menggunakan KBAT semasa berinteraksi dengan kanak-kanak dalam aktiviti bercerita supaya kemahiran KBAT dapat diterapkan kepada kanak-kanak.

\section{Elemen KBAT Dalam Pengajaran dan Pembelajaran}

Elemen KBAT iaitu aras mengaplikasi, menganalisis, menilai dan mencipta menjadi asas definisi KBAT yang diguna pakai dalam Kurikulum Standard Prasekolah Kebangsaan (KSPK, 2016) berdasarkan hierarki Taksonomi Bloom semakan Anderson \& Krathwohl (2001). Bagi melaksanakan KBAT dalam pengajaran dan pembelajaran, guru perlu membuat rujukan kepada standard pembelajaran yang dinyatakan dalam KSPK (2016). Standard 
pembelajaran merupakan pernyataan tentang kanak-kanak patut ketahui dan boleh lakukan. Guru perlu merancang pengajaran dan pembelajaran, dengan menyediakan rancangan pengajaran harian dan menyatakan objektif pembelajaran secara eksplisit. Guru juga hendaklah menyediakan aktiviti yang membolehkan kanak-kanak menggunakan KBAT dan bahan bantu belajar yang dapat mengalakkan KBAT. Guru melaksanakan pengajaran dan pembelajaran dengan mengemukakan soalan yang boleh menggalakkan KBAT. Suasana bilik darjah juga hendaklah membantu kanak-kanak menggunakan KBAT. Selain itu, guru perlu memastikan terdapat soalan KBAT dalam pentaksiran dan membuat refleksi tentang keberkesanan pengajaran dan pembelajaran menggunakan KBAT. Aktiviti bercerita dapat digunakan sebagai satu teknik untuk melatih kemahiran KBAT.

\section{Strategi Pengajaran dan Pembelajaran}

Strategi pengajaran dan pembelajaran yang berkesan perlu berpusatkan kanak-kanak. Interaksi guru dengan kanak-kanak dalam kelas hendaklah secara aktif melalui tugasan dan soalan yang mencabar minda mereka. Guru hendaklah mewujudkan suasana bilik darjah yang kondusif agar interaksi guru dengan kanak-kanak menggalakkan KBAT. Guru perlu merancang dan melaksanakan KBAT melalui pelbagai strategi yang bersesuaian dengan objektif pengajaran dan pembelajaran. Strategi yang betul dan tepat akan membantu mewujudkan suasana bilik darjah yang membolehkan kanak-kanak berfikir. Pelbagai strategi pengajaran boleh digunakan oleh guru untuk meningkatkan KBAT dan disesuaikan dengan tajuk dan tema yang dipilih agar ia bertepatan serta menarik perhatian dan minat kanak-kanak (Cocklin, 2012). Strategi pengajaran yang sesuai akan memberikan impak terhadap pengajaran dan pembelajaran yang diikuti oleh kanak-kanak (Fullan, 2011). Oleh itu, interaksi guru dengan kanak-kanak perlu menggunakan KBAT sewaktu bercerita secara maksimum agar murid berpeluang mempelajari KBAT secara tidak langsung.

\section{Kerangka Teori Kajian}

Kerangka teori kajian ini dibina untuk memberi penerangan mengenai perhubungan antara Teori Sosial Konstruktivisme (Vygotsky, 1978), pembelajaran berasaskan inkuiri (KSPK 2016) dan Taksonomi Bloom Semakan Semula (Anderson \& Krathwohl, 2001) dalam kajian interaksi guru dengan kanak-kanak melalui aktiviti bercerita. Teori Sosial Konstruktivisme yang dipelopori oleh Vygotsky adalah bersifat sosial yang menekankan interaksi interpersonal sama ada dengan rakan sebaya atau orang dewasa yang dapat membantu memperkembangkan pengetahuan individu. Menurut Vygotsky, kajian tentang perkembangan kognitif adalah proses penglibatan seseorang semasa perbincangan (Palincsar, 1998). Interaksi melalui perbincangan guru dengan kanak-kanak dapat meningkatkan konflik kognitif dan seterusnya membawa kepada perspektif yang baru.

Pembelajaran berasaskan inkuiri merupakan satu proses pengajaran dan pembelajaran yang berpusatkan kanak-kanak untuk melaksanakan aktiviti penerokaan, penyiasatan, penyoalan, berfikir secara refleksif dan penemuan ilmu baharu (KSPK, 2016). Kanak-kanak digalakkan bertanya soalan untuk mengelakkan berlakunya miskonsepsi dalam diri mereka (Guvercin \& Verbovskiy, 2014). Penglibatan kanak-kanak yang aktif dalam aktiviti penyoalan sewaktu proses pembelajaran dapat mengembangkan idea dan sesuatu konsep yang diperkenalkan oleh guru. Pendekatan inkuiri sesuai dalam interaksi guru dengan kanak-kanak sewaktu aktiviti bercerita kerana pada peringkat ini, kanak-kanak perlu diberikan bimbingan asas oleh guru bagi mencetuskan persoalan dan memupuk kanak-kanak untuk membuat penerokaan. Bimbingan guru sangat penting kerana kanak-kanak belum terbiasa dengan penyoalan yang menggunakan KBAT. 
Manakala Taksoomi Bloom telah disemak semula oleh Anderson \& Krathwohl (2001) yang menjadi rujukan dalam Kurikulum Standard Prasekolah Kebangsaan (2016) iaitu: mengaplikasi, menganalisis, menilai dan mencipta. Dalam konteks kajian ini, adalah diharapkan kanak-kanak dapat menggunakan KBAT yang berkesan. Proses berfikir kanakkanak dapat dilihat semasa guru menerapkan kemahiran berfikir aras tinggi dalam aktiviti bercerita.

\section{Metodologi Kajian}

\section{Reka Bentuk Kajian}

Kajian ini dijalankan secara kualitatif menggunakan kaedah kajian kes. Penggunaan kaedah kajian kes ini membolehkan penyelidik untuk mendapatkan maklumat yang terperinci tentang permasalahan yang dikaji (Creswell, 2012). Kaedah ini bersesuaian dengan tujuan kajian untuk mengkaji amalan interaksi guru dengan kanak-kanak yang berlaku semasa aktiviti bercerita menggunakan KBAT.

\section{Persampelan}

Kajian ini menggunakan pensampelan bertujuan iaitu lokasi dan individu dipilih dengan sengaja untuk memahami fenomena utama kajian. Sampel kajian terdiri daripada 4 orang guru tadika di daerah Muallim, Perak. Faktor pemilihan sampel adalah secara bertujuan iaitu guru yang dipilih adalah guru yang mengajar di tadika. Guru-guru ini bersedia untuk mengikuti kajian ini.

\section{Instrumen Kajian}

Data dikumpul dengan membuat triangulasi kepada kaedah dan sumber. Kaedah pengumpulan data yang digunakan adalah temu bual, pemerhatian, dan dokumen. Sumbersumber kepada data merupakan guru tadika dan dokumen pengajaran dan pembelajaran. Temu bual secara separa terbuka telah dijalankan dengan guru tadika terlibat. Menurut Creswell (2012), beberapa pemerhatian perlu dibuat agar pengkaji dapat lebih memahami lapangan kajian dan individu yang terlibat. Pengkaji telah membuat pemerhatian sebanyak dua kali untuk setiap orang guru sebagai bahan untuk menjayakan kajian ini. Aktiviti bercerita menggunakan 8 cerita iaitu Pepatung Yang Bongkak, Kebijaksanaan Sang Kancil, Raja Rimba, Ali Yang Baik Hati, Arnab Dan Kura-kura, Anjing Yang Tamak, Dua Sahabat dan Seekor Beruang Dan Helang Dengan Gagak. Penggunaan pelbagai kaedah pengumpulan data dapat memberikan data yang lebih dipercayai, mendalam, mewujudkan kesahan konstruk dan memberi gambaran holistik tentang pengajaran yang berlaku di dalam kelas (Muhammad Yaumi, 2014).

\section{Dapatan Kajian dan Perbincangan}

\section{Interaksi Guru Dengan Kanak-Kanak Menggunakan Kemahiran Berfikir Aras Tinggi}

\section{Pemerhatian}

Berdasarkan pemerhatian yang telah dibuat, didapati guru hanya menggunakan kemahiran berfikir aras rendah sahaja iaitu aras mengingat dan memahami. Berikut merupakan data yang diperolehi setelah pemerhatian dilakukan.

\section{Cerita 1 Pepatung Yang Bongkak}

Guru : Tengok muka burung, suka atau marah? 
Murid : Marah

Guru : Ini gambar apa kawan-kawan?

Murid : Pokok

\section{Cerita 2 Kebijaksanaan Sang Kancil}

Guru : Ini apa?

Murid : Buaya.

Guru : Ini ?

Murid : Lembu.

Guru : Kenapa buaya mengerang kesakitan?

Murid : Kena kayu

Guru : Ya, kena hempap kayu. Baiklah, siapakah yang menolong sang buaya?

Murid : Lembu

Guru : Kenapa buaya mengigit kaki si lembu? Sebab apa?

Murid : Jahat

Guru : Binatang apa yang selamatkan si lembu?

Murid : Kancil.

\section{Cerita 3 Raja Rimba}

Guru : Raja Rimba siapa tahu? Raja Rimba tu apa?

Murid : Harimau

Guru : Baiklah, kita tak boleh biarkan sang harimau buat seperti ini. Apa kata kita minta bantuan Sang Kancil, cadang Sang Monyet. Semua haiwan bersetuju dengan cadangan Sang Monyet. Baiklah, dia nak minta bantuan siapa?

Murid : Sang Monyet

Guru : Bukan. Sang Monyet cadang nak minta bantuan siapa?

Murid : Sang Kancil

Guru : Sang Kancil kata boleh. Dia boleh tolong tapi salah seekor binatang di hutan tu kena berjumpa dengan siapa?

Murid : Harimau

Guru : Tenggiling tahu tak binatang macam mana?

Murid : Tak tahu

Guru : Hei Sang Kancil kau tidak takut pada aku ya? Kata Sang Harimau pada siapa?

Murid : Sang Kancil

Guru : Kalau kau ganggu aku, aku akan pukul kau. Kata siapa?

Murid : Sang Kancil

Berdasarkan jadual 1 di atas, guru hanya menggunakan kemahiran berfikir aras rendah sahaja, iaitu mengingat dan memahami. Guru didapati tidak menggunakan kemahiran berfikir aras tinggi berdasarkan hierarki Taksonomi Bloom semakan Anderson \& Krathwohl (2001). Ini selaras dengan kajian mendapati guru masih kurang pengetahuan khususnya tentang KBAT, kurang kemahiran terhadap penerapannya serta sikap guru yang tidak menunjukkan komitmen yang tinggi untuk melaksanakannya (Mohd Nazri Hassan, Ramlee Mustapha, Nik Azimah Nik Yusuf \& Rosnidar Mansor, 2017). Guru sepatutnya berusaha untuk menggunakan pengetahuan mengenai KBAT semasa bercerita. Kesediaan dan keupayaan guru dalam menyampaikan KBAT masih rendah dan penggunaan kaedah konvensional dalam pengajaran masih meluas digunakan dalam kalangan guru (Mohamad Nurul Azmi et al. 2017). Guru juga perlu bersedia untuk menyampaikan KBAT semasa aktiviti pengajaran dan pembelajaran. 


\section{Pandangan Guru Kelas}

Pendapat guru tentang pengetahuan KBAT, menyatakan tahu tentang KBAT, tetapi tidak pasti akan penggunaannya dalam proses pengajaran dan pembelajaran. Sebagai contoh, apabila bercerita, mereka tidak dapat mengutarakan soalan aras tinggi kepada kanak-kanak. Mereka sering menggunakan perkataan "apa" dan "siapa" dalam sesi soal jawab semasa bercerita. Maknanya di sini, guru hanya mempunyai pengetahuan tentang KBAT tetapi tidak dapat untuk mengaplikasikan dalam interaksi dengan kanak-kanak sewaktu bercerita.

Pembentukan pemikiran aras tinggi dalam kalangan kanak-kanak bermula dengan penyediaan item KBAT yang melibatkan skop yang luas, kepelbagaian kaedah dan bahan rangsangan serta mencabar tetapi boleh ditaksir (KPM, 2013b). Guru perlu merancang dan melaksanakan item KBAT dalam pengajaran dan pembelajaran agar kanak-kanak dapat menggunakan pemikiran aras tinggi sejak kecil lagi. Kajian ini sesuai dengan kajian Sukiman, Noor Shah \& Mohd Uzi (2012) mendapati guru kurang mengamalkan soalan terbuka aras tinggi. Soalan berbentuk tersebut boleh menggalakkan pemikiran jika digunakan secara berkesan. Guru hendaklah menyediakan cerita-cerita yang sesuai dengan kanak-kanak dan memasukkan soalan-soalan terbuka yang mengandungi elemen KBAT semasa berinteraksi dengan kanakkanak.

Guru sepatutnya mendapatkan maklumat bagi perkaitan sesuatu perkara daripada kanakkanak berbanding mengabaikan jawapan yang tidak relevan (Williams, 2015). Melalui interaksi guru dengan kanak-kanak, sewaktu bercerita, guru perlu mengemukakan soalan supaya kanak-kanak dapat berfikir dan menggunakan pengetahuan yang diterima dengan pengetahuan sedia ada untuk membina pengetahuan baru. Jawapan yang diberikan oleh kanak-kanak hendaklah digunakan untuk mencungkil idea kanak-kanak dengan lebih banyak. Situasi ini mampu menggalakkan pemikiran aras tinggi dalam kalangan murid. Oleh hal yang demikian, guru perlu menggalakkan interaksi dengan murid menggunakan KBAT semasa bercerita agar pemikiran aras tinggi dapat ditanamkan kepada kanak-kanak.

\section{Analisis Dokumen}

Manakala, analisis dokumen pula dibuat berdasarkan lapan buah buku cerita. Buku cerita yang digunakan ialah Pepatung Yang Bongkak, Kebijaksanaan Sang Kancil, Raja Rimba, Pemotong Kayu Yang Jujur, Arnab Dan Kura-kura, Anjing Yang Tamak, Dua Sahabat Dan Seekor Beruang dan Helang Dengan Gagak. Kesemua buku ini mempunyai tema, kandungan dan tahap penglibatan yang ada kaitan dengan kanak-kanak di samping memupuk perasaan ingin tahu, perkembangan bahasa kanak-kanak, menggalakkan kanak-kanak berfikir, bersoal jawap dan memperoleh nilai-nilai murni. Perkembangan kognitif adalah proses penglibatan seseorang semasa perbincangan (Palincsar, 1998). Guru perlu menggalakkan kanak-kanak melibatkan aktiviti penerokaan yang berasaskan penyoalan (Carin \& Sund, 1971). Walau bagaimanapun, guru tidak menggunakan peluang yang ada semasa bercerita untuk memupuk perasaan ingin tahu melalui bahasa yang digunakan, tidak menggalakkan kanak-kanak menggunakan kemahiran berfikir aras tinggi semasa bersoal jawab dan tidak menerapkan nilai murni dengan cara yang berkesan. Di belakang buku cerita yang digunakan terdapat nilai moral yang dinyatakan. Guru sepatutnya bersoal jawab dengan menggunakan kemahiran berfikir aras tinggi dengan menyentuh nilai moral tersebut. Contoh cerita Arnab dan Kura-kura, guru hendaklah mengemukakan soalan seperti: bagaimana perasaan arnab apabila kalah? Mengapa? Kalau berjumpa dengan arnab itu, apa nasihat yang dapat diberikan? Melalui soal jawab menggunakan aras aplikasi, analisis, penilaian dan mencipta dengan kanak-kanak, guru boleh menerapkan nilai murni dengan cara yang lebih berkesan. Perancangan yang teratur dan mendapat bimbingan yang sewajarnya tentang KBAT dapat 
menyediakan interaksi guru dan kanak-kanak dalam aktiviti bercerita lebih menyeronokkan dan aktif.

\section{Kesimpulan}

Guru memainkan peranan penting dalam menentukan proses pengajaran dan pembelajaran dengan menggunakan KBAT. Penggunaan KBAT semasa di tadika dapat melatih pemikiran aras tinggi kanak-kanak di peringkat awal kanak-kanak. Penekanan KBAT di tadika adalah selaras dengan transformasi Pelan Pembangunan Pendidikan Malaysia (PPPM) 2013-2025 adalah untuk melahirkan generasi yang mempunyai pemikiran kritikal (KPM, 2013a). Dalam hal ini, guru perlu bersedia dan mempunyai pengetahuan yang luas mengenai KBAT agar elemen KBAT ini dapat diterapkan semasa proses pengajaran dan pembelajaran. Sokongan daripada pelbagai pihak terutama Kmenterian Pendidikan Malaysia perlu lebih dikhususkan dalam menguasai pengetahuan dan kemahiran KBAT untuk pembangunan professional guruguru. Guru perlu yakin bahawa menggunakan KBAT dapat membantu kanak-kanak menjadi lebih aktif dalam proses pembelajaran.

\section{Rujukan}

Abdullah, A.H., Aris, B., Saud, M.S., Boon, Y. \& Awang Ali, S.A. (2015). Pelaksanaan Kemahiran Berfikir Aras Tinggi (KBAT): Isu Dan Cabaran Dalam Aspek Kurikulum,

Pedagogi Dan Pentaksiran. Seminar Kebangsaan Majlis Dekan-Dekan Pendidikan Universiti Awam, 14-15 September, P. 77-88.

Anderson, L.W., \& Krathwohl D.R. (Eds.) (2001). A Taxonomy For Learning, Teaching And Accessing: A Revision Of Bloom's Taxonomy Of Educational Objective. New York: Longman

Carin, A.A. \& Sund R.B. (1971). Developing Question Techniques: A Self-Concept Approach. Columbus, OH: Charles E. Merrill.

Conklin, W. (2012). Strategies For Developing Higher Order Thinking Skills. California: Shell Education

Creswell, J. W. (2012) Education Research: Planning, Conducting, And Evaluating Quantitative And Qualitative Research 4 Th Edition University Of NebraskaLincoln.

Fullan (2011). Makna Baharu Perubahan Pendidikan. Terjemahan. Mastuti Isa \& Asia Salleh. Kuala Lumpur. Institut Terjemahan Negara Malaysia.

Guvercin, S., \& Verbovskiy, V. (2014). The Effect of Problem Posing Tasks Used in Mathematics Instruction to Mathematics Academic Achievement and Attitudes Toward Mathematics. International Online Journal of Primary Education, 3(2), 59 65.

Kassim, N., \& Zakaria, E. (2015). Integrasi Kemahiran Berfikir Aras Tinggi Dalam Pengajaran Dan Pembelajaran Matematik: Analisis Keperluan Guru. Proceeding Book Education Gradute Regional. Conference In Counseling Centre Profesional Counselor Education Laboratory In The State University Of Medan. P. 60-67.

Kementerian Pendidikan Malaysia, (2013a) Pelan Pembangunan Pendidikan Malaysia (PPPM) 2013 - 2025 (Pendidikan Prasekolah Hingga Lepas Menengah). Putrajaya.

Kementerian Pendidikan Malaysia, (2013b). Pentaksiran Kemahiran Berfikir Aras Tinggi. Putrajaya; Lembaga Peperiksaan Malaysia

Kementerian Pendidikan Malaysia Kementerian Pendidikan Malaysia (2016). Kurikulum Standard Prasekolah Kebangsaan. Kuala Lumpur: Bahagian Perkembangan Kurikulum.

Mohamad Nurul Azmi Mat Nor \& Nurzatulshima Kamarudin (2016) Penyebatian kemahiran berfikir aras tinggi (KBAT) dalam proses pengajaran dan pembelajaran di Institut 
Pendidikan Guru (IPG), Malaysian Journal Of Higher Order Thinking Skills In Education, 2, 199-214

Mohd Nazri Hassan, Ramlee Mustapha, Nik Azimah Nik Yusuff \& Rosnidar Mansor (2017) Pembangunan Modul Kemahiran Berfikir Aras Tinggi Di Dalam Mata Pelajaran Sains Sekolah Rendah: Analisis Keperluan Guru. Sains Humanika, 9, 119-125

Muhammad Yaumi. (2014). Action Research: Teori, Model Dan Aplikasinya. Indonesia: Kencana Prenadamedia Group.

Norazilawati Abdullah, Noraini Mohd Noh, Mahizer Hamzah \& Nik Azmah Nik Yusuf (2014). Kesediaan guru sains dan matematik dalam pelaksanaan Kurikulum Standard Sekolah Rendah. Jurnal Pendidikan Sains dan Matematik Malaysia, 4(1), 81-96

Palinscar, A. S. (1998). Social constructivist perspectives on teaching and learning. Annual Review Psychology 49: 345- 375.

Sukiman Saad, Noor Shah Saad, \& Mohd Uzi Dollah (2012). Pengajaran Kemahiran Berfikir Aras Tinggi: Persepsi Dan Amalan Guru Matematik Semasa Pengajaran Dan Pembelajaran Di Bilik Darjah. Jurnal Pendidikan Sains \& Matematik Malaysia, 2(1), 18-36.

Suppiah Nachiappan. (2015). Panduan Pendidikan Awal Kanak-Kanak: Teori, Model, Kaedah dan Aktiviti ke Arah Perkembangan Kognisi. Tanjong Malim: Penerbit Universiti Pendidikan Sultan Idris.

Vygotsky, L.S. (1978). Mind in Society: The Development of Higher Mental Process. Cambridge: Harvard University Press.

Williams, R.B. (2015). Higher Order Thinking Skills: Challenging All Students To Achieve. New York: Skyhorse Publishing.

Zamri Mahmood \&Nor Razah Lim (2011). Kepelbagaian Kaedah Penyoalan Lisan Dalam Pengajaran Guru Bahasa Melayu: Kaedah Pemerhatian. Jurnal Pendidikan Bahasa Melayu, ISSN: 2180-4842, Vol. 1, Bil. 1 (Mei 2011): 51-65 